\title{
Evaluation of and Fracture Behavior of Alloy 90 Sheets
}

\author{
Alapati Venkateswarlu ${ }^{1,}$ Prof. Dr.Virendra Kumar Sharma ${ }^{2}$, \\ Dr.L.Rama Krishna ${ }^{3}$ \\ 1. Research Scholar Bhagwant University, Ajmer, India \\ 2. Vice chancellor Bhagwant University, Ajmer, India \\ 3. Scientist- 'E,' International Advanced Research Centre for powder Metallurgy and New Materials \\ (ARCI).Hyderabad
}

\begin{abstract}
ALLOY-90 refers to a family of austenitic nickel-based super alloys. Nimonic alloys typically consist of roughly $80 \%$ nickel and $20 \%$ chromium with additives such as titanium and aluminium. Nickel-based superalloys, among several high temperature structural alloys, are the prime materials for numerous advanced high temperature structural components. Several advanced processing technologies, such as isothermal forging, equiangle extrusion, investment casting, directional solidification and single crystal technologies, similar and dissimilar metal joining, destructive and non- destructive testing too have also evolved.

In the past, a few attempts have been made to study the deformation behavior and Fracture behavior of the alloy 90 sheets for sheet metal applications. However, these studies were limited to different commercial grades such as cold rolled sheets of thicknesses upto $2 \mathrm{~mm}$. None of these studies have addressed the influence of microstructure and texture for ultra-thin sheet applications. Hence, a comprehensive study has been undertaken to evaluate the ambient temperature deformation characteristics as a function of degree of cold rolling and ageing.

In order to determine the tensile properties, tensile tests are conducted on the alloy-90 sheets of $1 \mathrm{~mm}$ and $0.5 \mathrm{~mm}$ thicknesses in different heat treat conditions in different specimen orientations namely $R, R+30^{\circ}$, $R+45^{\circ}, R+60^{\circ}$ and $R T$. The fracture behavior of the alloy sheets are studied to determine the mode of fracture. present work includes comparison of tensile properties of macro and micro specimens of alloy 90 sheet and properties evaluated in the present work include tensile flow behavior in various microstructural conditions such as Cold rolled, Solution treated, aged for different times.
\end{abstract}

Key words: Formability, Alloy 90, Impact

\section{Introduction}

ALLOY-90 SHEETS might be used in any environment that requires resistance to heat and corrosion but where the mechanical properties of the metal must be retained. Improved properties may be achieved by modifying alloy chemistry and processing route. The high temperature strength of these alloys is not only a function of microstructural changes in the material, but the result of a competition between two deformation modes, i.e. the normal low to mid temperature tensile deformation and deformation via a creep mode.Nickel based super alloys typically have austenitic face-centered cubic (fcc) crystal structure and hence, are expected to show low degrees of anisotropy (both in in-plane and through - thickness directions) in their mechanical properties. Such anisotropy of engineering materials manifests itself as a variation in the mechanical properties in different test directions and the same is important for the following reasons:

The Alloy-90, whose formability (drawability) is studied in the present investigation is a wrought nickel base super alloy and derives its strength from precipitation of fine, coherent $\gamma^{\prime}$ within fcc $\gamma$ matrix. The alloy has excellent ambient and elevated temperature deformability with good welding characteristics. Alloy 90 is a Nickel-Chromium-Cobalt alloy being precipitation hardenable, having high stress-rupture strength and creep resistance at high temperatures up to about $950^{\circ} \mathrm{C}\left(1740^{\circ} \mathrm{F}\right)$. It is widely used and a well proven alloy in high temperature conditions.

\section{Chemical Composition Of Alloy-90}

Chemical Composition of alloy-90 is given in Table 1. It describes that the actual chemical compositions of different alloys 
Evaluation Of Tensile Deformation And Fracture Behavior Of Alloy 90 Sheets

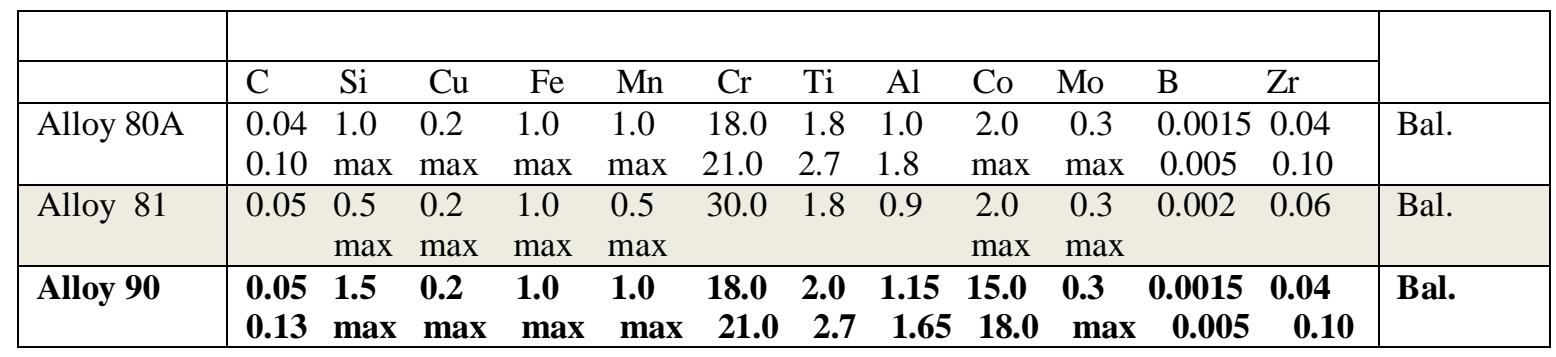

Table.1

III. Typical Properties Of Alloy 90

Typical properties of Alloy-90 are covered in the following table.

\begin{tabular}{|lcc|}
\hline Property & Metric & Imperial \\
\hline Density & $8.18 \mathrm{~g} / \mathrm{cm}^{3}$ & $0.296 \mathrm{lb} / \mathrm{in}^{3}$ \\
Melting point & $1370{ }^{\circ} \mathrm{C}$ & $2500^{\circ} \mathrm{F}$ \\
Co-Efficient of Expansion & $12.7 \mu \mathrm{m} / \mathrm{m} .{ }^{\circ} \mathrm{C}$ & $7.1 \times 10^{-6} \mathrm{in} / \mathrm{in} .{ }^{\circ} \mathrm{F}$ \\
Modulus of rigidity & $\left(20-100{ }^{\circ} \mathrm{C}\right)$ & $\left(70-21{ }^{\circ} \mathrm{F}\right)$ \\
Modulus of elasticity & $82.5 \mathrm{kN} / \mathrm{mm}^{2}$ & $11966 \mathrm{ksi}$ \\
& $* 213 \mathrm{kN} / \mathrm{mm}^{2}$ & $30894 \mathrm{ksi}$ \\
\hline
\end{tabular}

* Solution Annealed + Aged **Spring Temper and Aged Table.2

Alloy-90 is widely used as cold rolled sheet product for a number of high temperature applications such as aircraft turbine and land-based-turbine engine components, due to its high creep strength and superior oxidation resistance. However some of the recent applications of Alloy-90 sheet, especially the ultra thin sheets for thermal protection systems, need specific studies to evaluate in detail the factors that influences the cold rolling and drawability. Effect of ageing is the two most critical areas, which provide the scientific basis to this characterization. The properties evaluated in the present paper include tensile flow behaviour in various microstructural conditions such as Solution treated, aged for different times, apart from the microstructure as well as texture determination. The data obtained are analyzed for anisotropy in tensile properties (strength and ductility) and yield behaviour. The tensile properties were determined in five different test directions, namely $\mathrm{P}$ (Longitudinal Direction i.e. parallel to the rolling direction), $\mathrm{P}+30^{\circ}, \mathrm{P}+45^{\circ}, \mathrm{P}+60^{\circ}$ and $\mathrm{P}+90^{\circ}$ (perpendicular to the rolling direction). These data as a function of ageing and sheet thickness along with the details of microstructure and texture, when evaluated, analyzed and obtained the relevant yield properties, have become valuable and essential data inputs for the principal aim of the paper.

\section{Evolution Of Research In Methods Of Tensile Deformation And Fracture Behavior}

4.1 Deep drawing: The numerical difficulty in the finite element analysis of the deep drawing processes arises due to the existence of compressive stress in the sheet plane and the occurrence of unloading.

4.2 Yield Behaviour: The yield behaviour and the characteristics that influence the several structural materials have been the subjects of scientific studies for sheet metal applications. Recent studies have also attempted to correlate the microstructure, texture, in-plane anisotropy in yield stress and work hardening exponent to the deep drawability. However such studies required to be conducted in case of the Alloy 90 as this particular alloy has been the prime candidate material chosen for ultra-thin sheet applications for honeycomb structures of thermal protection systems. Nickel based super alloys typically have axi-symmetric face-centered cubic (fcc) crystal structure and hence, are expected to be isotropic. Studies have been reported in the literature in which these symmetric crystal structured alloys are found to exhibit high degree of isotropy in their tensile deformation . However, some of the recent studies revealed especially those on Al-Li alloys (though they too are of fcc crystal structure) have exhibited considerable degree of anisotropy in mechanical properties due to strong crystallographic texture, often developed due to extensive cold working. Similarly, the ageing conditions too affect the yield behavior and also anisotropy in the yielding significantly. Such an anisotropy of engineering materials manifests itself as a variation in the mechanical properties in different test directions and the same is important for the following reasons: (a) directionality in the properties may be utilized to obtain improved formability; (b) service performance of a material in a particular orientation may be selectively improved and most importantly, (c) components may become susceptible to failure in an unfavorable direction, with 
catastrophic consequences. we report the tensile deformation behavior, anisotropy in tensile properties and yield loci in addition to the microstructural and textural effects on the observed deformation behavior.

4.3 Transient flow behavior: The prominent objective of the present study is that the alloy in solution treated condition exhibit transient flow behavior at lower strain. Such behavior has been reported earlier in several FCC materials with low stacking fault energy such as $\alpha$-brass, silver and austenitic stainless steels.

Metals with somewhat higher stacking fault energies, namely copper and silver, exhibit more negative values of $n_{2}$ and lower values of $\varepsilon_{\mathrm{L}}(3 \%)$. Aluminium and nickel, with the highest stacking fault energies in this series obey the Hollomon relation and do not exhibit any transition in flow behaviour.

\section{Affect Of Specimen Orientation}

The other aspect to be investigated in the present study is the affect of specimen orientation with respect to rolling direction on strain hardening behavior of the alloy. Strain hardening rate, $\theta(=\mathrm{d} \sigma / \mathrm{d} \varepsilon)$ versus strain plots for the alloy in solution treated as well as aged conditions and for different specimen orientations. while the alloy specimen with longitudinal orientation (i.e., parallel to rolling direction), exhibit marginally highest strain hardening rates, specimen with long transverse orientation exhibits lowest strain hardening rate both in solution treated and aged conditions. However, for all other orientations (i.e., $\mathrm{P}+30^{\circ}, \mathrm{P}+45^{\circ}$ and $\mathrm{P}+60^{\circ}$ ), the strain hardening rate data is fairly very close and lie in between those of longitudinal and Longitudinal Transverse orientations. Such a behavior is consistent with regard to tensile properties.

\section{Material Model And Properties Of Tooling}

In the present study, an effort is made to comprehensively evaluate and rationalize the effect of ageing on the nature of deformation (strain hardening behaviour) and formability Characteristics. Despite weak crystallographic texture and excellent ductility and high work hardening exponents, the alloy 90 sheet exhibits significant extent of in-plane anisotropy in its tensile properties and yield loci. The of microstructural features, mainly such as precipitation of $\square$ ' strengthening phase obtainable by ageing after cold rolling and solutionizing, was found not to alter the nature of deformation significantly. However the alloy in aged condition shows reduced degree of anisotropy with significantly improved strength characteristics and moderate decrease in drawability. The alloy under tensile deformation exhibits mixed nature of fracture, comprising of a predominant ductile micro-dimpled fracture with minor degree of transgranular shear fracture. Transmission electron microscopy (TEM) is used to examine the specimens to record the microstructural characteristics at significantly higher magnifications.

\section{Chemical Composition Of The Experimental Alloy Sheet:}

Table 3: Chemical composition of the experimental alloy sheet is shown in Table 3. It shows that the change of $\%$ of composition of various elements for experimental purpose

\begin{tabular}{|c|c|c|c|c|c|c|c|c|c|c|c|}
\hline Element & $\mathrm{C}$ & Co & $\mathrm{Cr}$ & Mo & Al & $\mathbf{S i}$ & $\mathbf{T i}$ & Mn & B & $\mathbf{P}$ & $\mathbf{N i}$ \\
\hline $\begin{array}{l}\text { Actual } \\
\text { Composition, } \\
\text { (wt. \%) - } \\
1.0 \mathrm{~mm} \text { thick } \\
\text { sheet } \\
0.5 \mathrm{~mm} \text { thick } \\
\text { sheet }\end{array}$ & $\begin{array}{l}0.058 \\
0.053\end{array}$ & $\begin{array}{l}15.03 \\
15.36\end{array}$ & $\begin{array}{l}18.65 \\
18.90\end{array}$ & $\begin{array}{l}0.28 \\
0.295\end{array}$ & $\begin{array}{l}1.55 \\
1.34\end{array}$ & $\begin{array}{l}1.45 \\
1.05\end{array}$ & $\begin{array}{l}2.10 \\
2.04\end{array}$ & $\begin{array}{l}0.42 \\
0.43\end{array}$ & $\begin{array}{l}0.001 \\
0.095\end{array}$ & $\begin{array}{l}0.005 \\
0.005\end{array}$ & $\begin{array}{l}\text { Bal. } \\
\text { Bal }\end{array}$ \\
\hline $\begin{array}{l}\text { Specified } \\
\text { composition }\end{array}$ & $\begin{array}{l}0.05- \\
0.13 \\
\end{array}$ & $\begin{array}{l}15- \\
18 \\
\end{array}$ & $\begin{array}{l}18- \\
21\end{array}$ & $\begin{array}{l}0.3- \\
\max \end{array}$ & $\begin{array}{l}1.15- \\
1.65 \\
\end{array}$ & $\begin{array}{l}1.5- \\
\max \end{array}$ & $\begin{array}{l}2.0- \\
2.7\end{array}$ & $\begin{array}{l}1.0- \\
\max \end{array}$ & $\begin{array}{l}0.0015 \\
0.005 \\
\end{array}$ & -- & Bal. \\
\hline
\end{tabular}

Table -3

\section{Research Methodology}

As the received material is in the form of cold rolled and solution treated sheets of thicknesses $1 \mathrm{~mm}$ and $0.5 \mathrm{~mm}$. The cold rolled sheets are solution treated at $1110 \pm 10^{\circ} \mathrm{C}$ for $5-15$ minutes, followed by air cooling. The present work aims at comprehensive evaluation of monotonic tensile deformation, work hardening and drawability characteristics of Nimonic alloy 90 sheet. The data obtained from the monotonic tensile tests are integrally used to determine the drawability characteristics. Transmission electron microscopy (TEM) is used to examine the specimens to record the microstructural characteristics at significantly higher magnifications

The evaluation of Tensile properties and Fracture behavior requires the determination of properties in various test directions. The number of directions to be tested depends upon the product type, such as plate, 
sheet, extrusion, forging and castings. Mechanical properties are generally evaluated in three orthogonal directions namely,

(a) The longitudinal direction (where the stress axis is parallel to the direction of rolling, forging etc. and designated as $\mathrm{P}$ in deformation studies),

(b) The long transverse direction (where the stress axis is perpendicular to the direction of rolling, forging etc and lies in the plane of rolling, forging etc designated as $\mathrm{P}+90^{\circ}$ in deformation studies) and

(c) The short transverse direction (where the stress axis is along the thickness direction of the product and designated as PL or PT in deformation studies).

The properties evaluated in the present work include tensile flow behaviour in various microstructural conditions such as Solution treated, aged for different times, apart from the microstructure as well as texture determination. The data obtained is analyzed for anisotropy

in tensile properties (strength and ductility) and yield behaviour. The tensile properties are determined in five different test directions, namely $\mathrm{P}, \mathrm{P}+30^{\circ}, \mathrm{P}+45^{\circ}, \mathrm{P}+60^{\circ}$ and $\mathrm{P}+90^{\circ}$. These data as a function of ageing and sheet thickness along with the details of microstructure and texture, when evaluated, analyzed and obtained the relevant yield properties.

\section{Results}

The alloy sheet in the as-received, i.e., solution treated and cold rolled condition was further subjected to aging treatment at $1110 \mathrm{~K}$ in a vacuum furnace for different durations. Specimens for microstructure (both optical and transmission electron microscopy), and texture evaluation, Vicker's hardness and tensile property evaluation are withdrawn from the vacuum heat treatment furnace after appropriate duration of ageing treatment. The specimens were then processed further. Based on the aging curve (variation of Vickers macro hardness with aging time), determined and shown in Fig.1, tensile properties were evaluated on specimens from 0.5 and $1 \mathrm{~mm}$ thick alloy sheets that were aged at this temperature for select durations of 1,8 and 20 hours.

The effect of ageing is discussed in terms of variation in hardness (Vickers hardness number obtained using $10 \mathrm{Kg}$ load) for different ageing conditions as well as sheet thicknesses. In both sheet thicknesses the hardness increases significantly within 1 hour ageing at $1110 \mathrm{~K}$. Such an increase is significantly higher for thinner sheet of $0.5 \mathrm{~mm}$ thickness. Further ageing to $8 \mathrm{~h}$ increases the hardness marginally (Fig. I \& Fig. IIand Table -4). Further increase in ageing time decreases the hardness significantly. The hardness values obtained on specimens aged to $20 \mathrm{~h}$ show a decrease in hardness values that are up to $20 \%$ lower as compared the $8 \mathrm{~h}$ aged condition, depending upon sheet thickness. Hence, the present nimonic alloy attains peak hardness at $8 \mathrm{~h}$ ageing, which is designated as peak aged condition. Limited tensile tests conducted as a function of ageing too reveal similar trends. Such tensile data are included in Table .4 for the sake of comparison.

Table.4:Vickers hardness and Yield stress values of alloy 90 sheet in cold rolled and Solution treated and different aged Conditions of $1 \mathrm{~mm}$ and $0.5 \mathrm{~mm}$ thickness

\begin{tabular}{|l|c|c|c|c|}
\hline \multirow{2}{*}{ Condition } & \multicolumn{3}{|c|}{ Vickers hardness number } & \multicolumn{2}{c|}{$\begin{array}{c}\text { Yield Stress } \\
\text { at }\end{array}$} \\
\cline { 2 - 5 } & $\mathbf{1} \mathbf{~ m m}$ & $\mathbf{0 . 5} \mathbf{~ m m}$ & $\mathbf{1} \mathbf{~ m m}$ & $\mathbf{0 . 5} \mathbf{~ m m}$ \\
\hline Initial & 262 & 287 & 539 & 689 \\
\hline $1110 \mathrm{~K} / 2$ hour & 324 & 366 & 789 & 875 \\
\hline $1110 \mathrm{~K} / 8$ hours & 339 & 410 & 829 & 980 \\
\hline $1110 \mathrm{~K} / 19$ hours & 328 & 339 & 752 & 819 \\
\hline
\end{tabular}

Table.4

Fig -I and Fig -II are shows that Vickers hardness and Yield stress values of alloy 90 sheet in cold rolled ,Solution treated vs different aged Conditions at $1110^{\circ} \mathrm{k}$ of $1 \mathrm{~mm}$ and $0.5 \mathrm{~mm}$ thickness graphically . 


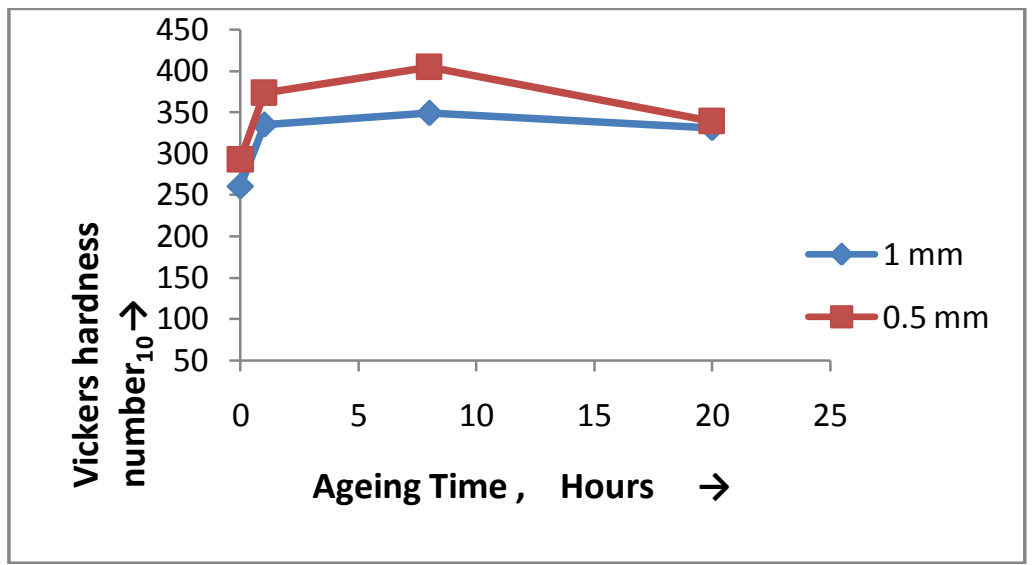

Fig-I

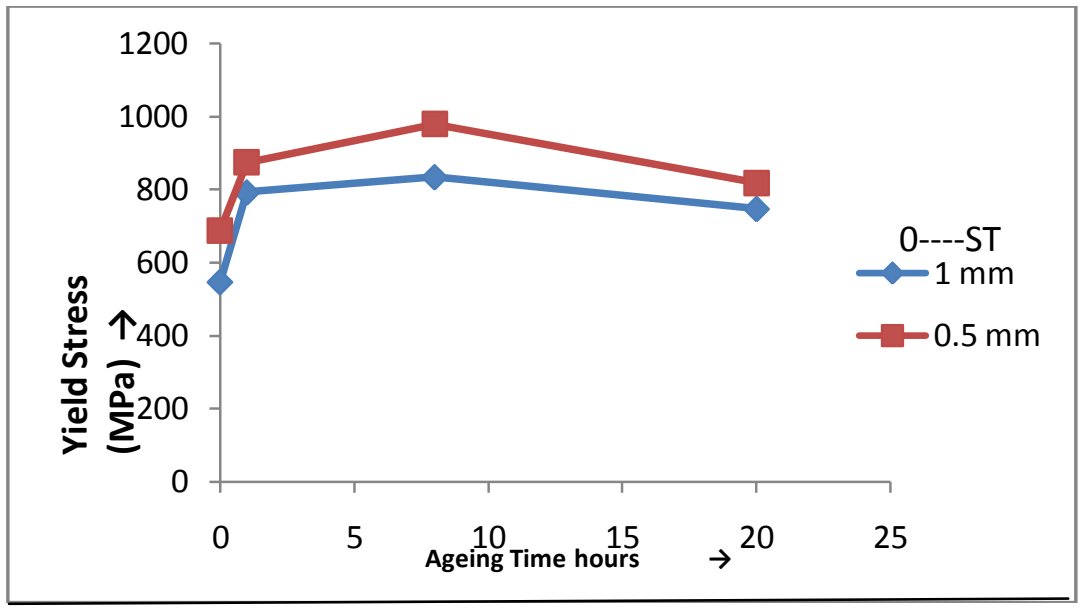

Fig-II

\subsection{TENSILE PROPERTIES AND YIELD BEHAVIOR}

The ageing conditions too affect the yield behavior and also anisotropy in the yielding significantly $[2,133]$. Such an anisotropy of engineering materials manifests itself as a variation in the mechanical properties in different test directions and the same is important for the following reasons: (a)directionality in the properties may be utilized to obtain improved formability;

(b) Service performance of a material in a particular orientation may be selectively improved and most importantly,

(c) Components may become susceptible to failure in an unfavorable direction, with catastrophic consequences.

Both the aspects of yield behavior and the anisotropy can be studied by evaluating the tensile properties in various in-plane directions, namely the longitudinal ( $\mathrm{P}$, along the rolling direction) and $30^{\circ}, 45^{\circ}$ and $60^{\circ}$ to the rolling direction, designated as $\mathrm{P}+30^{\circ}, \mathrm{P}+45^{\circ}$ and $\mathrm{P}+60^{\circ}$, respectively as well as long - transverse (PT, perpendicular to the rolling direction). Alternatively, the yield behavior can also be studied by determining the yield loci using asymmetrical Knoop micro hardness indenter [130,137]. In the present paper, we report the tensile deformation behavior, tensile properties and yield loci in addition to the micro structural and textural effects on the observed deformation behavior.

\subsection{Experimental Details}

In tensile properties has been determined by means of tests conducted on specimens oriented differently with respect to the rolling direction. The details of the alloy studied and specimen geometries employed are given in the Table IV.1. The orientation code for the specimens employed has been shown in Fig. I.1. After machining the tensile test specimens using the wire cut EDM machine, the specimens were given a fine ground finish especially in the fillet region in order to reduce the possible notch effects from the deep machining marks. Tensile tests at room temperature were conducted on a computer controlled servo-hydraulic INSTRON 5500R universal testing machine at a cross-head speed of $1 \mathrm{~mm}$ per minute. The tests were conducted as per the ASTM 
Standard E-8 [138]. The strain was monitored with the help of axial extensometer of $30 \mathrm{~mm}$ gauge length. The engineering stress-strain data thus obtained were further analyzed with the help of a specially developed computer program to determine the values of the work hardening coefficient (n) in the Hollowman's equation: $\square \square=\square \square \square{ }_{\mathrm{p}}^{\mathrm{n}}$, Where $\square$ is the true stress and $\square_{\mathrm{p}}$ the true plastic strain. Obtained Results were tabulated

\section{Table IV.1: Is describes that the details of direction of study and specimen geometry of Test specimen Table IV.1}

\begin{tabular}{|l|l|c|c|c|c|}
\hline \multirow{2}{*}{ Alloy Designation } & \multicolumn{1}{|c|}{$\begin{array}{c}\text { Direction } \\
\text { Studied }\end{array}$} & $\begin{array}{c}\text { Type of } \\
\text { Specimen }\end{array}$ & $\begin{array}{c}\text { Thicknes } \\
\mathbf{s} \\
(\mathbf{m m})\end{array}$ & $\begin{array}{c}\text { Width } \\
(\mathbf{m m})\end{array}$ & $\begin{array}{c}\text { Gauge } \\
\text { Length } \\
(\mathbf{m m})\end{array}$ \\
\hline $\begin{array}{c}\text { Alloy } 90 \text { Sheet } \\
\begin{array}{c}1 \quad \text { and } 0.5 \mathrm{~mm} \\
\text { thick) }\end{array}\end{array}$ & $\begin{array}{l}\mathrm{P}, 30^{\circ}, 45^{\circ}, 60^{\circ}, \\
\mathrm{PT}\end{array}$ & \multicolumn{1}{|c|}{ Flat } & 1 and 0.5 & 10 & 30 \\
\hline
\end{tabular}

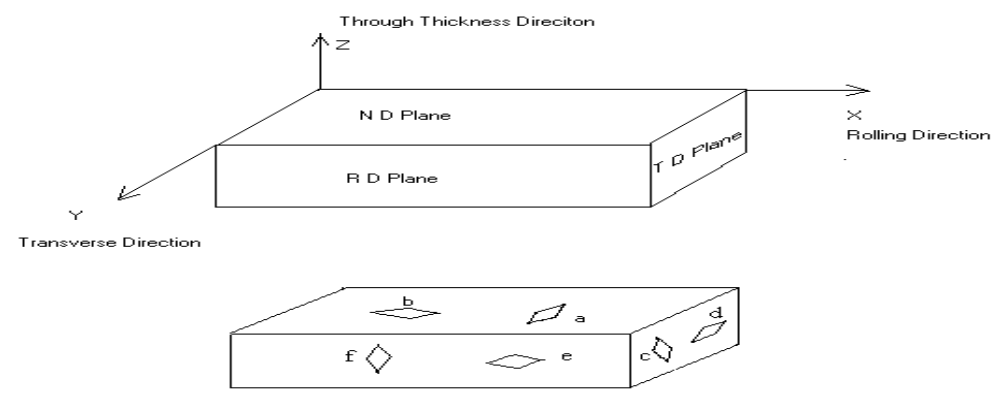

Fig.1.1

Fig1.1: A three dimensional representation of rolled sheet and orientations on three orthogonal planes.

\subsection{Tensile properties and its orientation dependence}

\section{Results and Discussion}

The engineering stress-strain curves obtained from the tensile testing of the alloy sheets of $1 \mathrm{~mm}$ and $0.5 \mathrm{~mm}$ thickness in the Cold Rolled, Solution treated and peak aged conditions are shown in Figs. IV.1 - IV.2 and Figs. IV.4 - IV.5. These figures include the tensile test data obtained from the specimens of different orientations from the rolling directions, $\mathrm{P}$ (parallel to rolling direction) $, 30^{\circ}, 45^{\circ}$ and $60^{\circ}$ to the rolling direction, respectively and PT (perpendicular to the rolling direction). Both alloy sheets in the Cold Rolled and Solution Treated condition exhibit significantly lower strength levels and higher strains to fractures as compared to the peak aged condition. An interesting aspect in the observed tensile deformation has been the fact that unlike the alloy sheet in Cold Rolled, Solution treated and, the peak aged alloy sheets were found to exhibit significant extent of serrated plastic flow.

Tables IV.2 to IV.5 include the tensile properties of alloy 90 sheet of $1 \mathrm{~mm}$ and $0.5 \mathrm{~mm}$ thickness in the cold rolled and solution treated, cold rolled, solution treated and $8 \mathrm{~h}$ aged (peak aged) conditions as a function of orientation with respect to the rolling direction. The properties evaluated include the $\%$ of yield stress (YS), the ultimate tensile stress (UTS), the total elongation, the uniform strain ( $\square_{\mathrm{u}}$ ) and the work hardening exponent (n). These are graphically shown in Figs. IV.3(a),(b)and(c) and IV.6 (a),(b) and (c).

Table IV.2: In tensile properties of alloy 90 sheet of $1 \mathrm{~mm}$ thickness in the Cold rolled and Solution treated condition. (Tests were conducted at room temp at an initial strain rate of $10^{-4} \mathrm{~s}^{-1}$ ).

\begin{tabular}{|c|l|c|c|c|c|c|}
\hline \multirow{2}{*}{$\begin{array}{c}\text { S.N } \\
\mathbf{o}\end{array}$} & \multirow{2}{*}{ Property } & \multicolumn{5}{|c|}{ Specimen orientation with respect to the Rolling } \\
Direction, Deg \\
\cline { 3 - 7 } & & $\mathbf{P}$ & $\mathbf{3 0}$ & $\mathbf{4 5}$ & $\mathbf{6 0}$ & PT \\
\hline 1 & \% of Y.S, MPa & 556 & 489 & 484 & 485 & 460 \\
\hline 2 & UTS, MPa & 963 & 847 & 845 & 780 & 808 \\
\hline 3 & $\begin{array}{l}\text { Total Elongation, \% } \\
\end{array}$ & 30.6 & 51 & 53.4 & 53.2 & 41.8 \\
\hline 4 & Work Hardening exponent $n$ & 0.39 & 0.38 & 0.43 & 0.40 & 0.39 \\
\hline 5 & $\sigma_{\text {UTS } /} \sigma_{Y}$ & 1.73 & 1.73 & 1.75 & 1.60 & 1.75 \\
\hline
\end{tabular}

Table IV.2 
Table IV.3: In tensile properties of alloy 90 sheet of $1 \mathrm{~mm}$ thickness in the peak aged (Cold Rolled ,Solution Treated at $1110^{0} \mathrm{~K} / 8 \mathrm{~h}$ aged) condition. (Tests were conducted at room temp at an initial strain rate of $10^{-4} \mathrm{~s}^{-1}$ ).

\begin{tabular}{|c|l|c|c|c|c|c|}
\hline \multirow{2}{*}{$\begin{array}{c}\text { S.N } \\
\text { o }\end{array}$} & \multicolumn{5}{|c|}{ Property } & \multicolumn{5}{|c|}{ Direction, Deg orientation with respect to the Rolling } \\
\cline { 3 - 7 } & & $\mathbf{P}$ & $\mathbf{3 0}$ & $\mathbf{4 5}$ & $\mathbf{6 0}$ & PT \\
\hline 1 & $0.2 \%$ Y.S, MPa & 845 & 840 & 821 & 795 & 784 \\
\hline 2 & UTS, MPa & 1230 & 1192 & 1188 & 1155 & 1164 \\
\hline 3 & Total Elongation, \% & 18.40 & 38.80 & 36.40 & 40.10 & 34.50 \\
\hline 4 & Work Hardening exponent $\mathrm{n}$ & 0.26 & 0.29 & 0.30 & 0.30 & 0.29 \\
\hline 5 & $\sigma_{\mathrm{UTS}} / \sigma_{\mathrm{Y}}$ & 1.50 & 1.41 & 1.40 & 1.45 & 1.48 \\
\hline
\end{tabular}

Table IV.3

Table IV.4:In tensile properties of alloy 90 sheet of $0.5 \mathrm{~mm}$ thickness in the Cold rolled and Solution treated condition. (Tests were conducted at room temp at an initial strain rate of $10^{-4} \mathrm{~s}^{-1}$ ).

\begin{tabular}{|c|l|c|c|c|c|c|}
\hline \multirow{2}{*}{$\begin{array}{c}\text { S.N } \\
\text { o }\end{array}$} & \multicolumn{2}{|c|}{ Property } & \multicolumn{5}{|c|}{ Specimen orientation with respect to the Rolling } \\
\cline { 3 - 7 } & & \multicolumn{5}{|c|}{ Direction, Deg } \\
\hline 1 & $0.2 \%$ Y.S, MPa & 704 & $\mathbf{3 0}$ & $\mathbf{4 5}$ & $\mathbf{6 0}$ & PT \\
\hline 2 & UTS, MPa & 998 & 929 & 954 & 636 & 615 \\
\hline 3 & Total Elongation, \% & 34.5 & 40.8 & 43.2 & 950 & 909 \\
\hline 4 & Uniform Strain, $\varepsilon_{\mathbf{u}}$ & 0.35 & 0.36 & 0.36 & 0.38 & 42.3 \\
\hline 5 & $\sigma_{\text {UTS }} \sigma_{\mathrm{Y}}$ & 1.42 & 1.38 & 1.43 & 1.49 & 0.36 \\
\hline
\end{tabular}

Table IV.4

Table IV.5: In tensile properties of alloy 90 sheet of $0.5 \mathrm{~mm}$ thickness in the peak aged (Cold Rolled ,Solution Treated at $1110^{0} \mathrm{~K} / 8 \mathrm{~h}$ aged) condition. (Tests were conducted at room temp at an initial strain rate of $10^{-4} \mathrm{~s}^{-1}$ ).

\begin{tabular}{|c|l|c|c|c|c|c|}
\hline \multirow{2}{*}{$\begin{array}{c}\text { S. } \\
\text { No }\end{array}$} & \multicolumn{2}{|c|}{ Property } & \multicolumn{5}{|c|}{ Specimen orientation with respect to the } \\
Rolling Direction, Deg \\
\hline 1 & & P & $\mathbf{3 0}$ & $\mathbf{4 5}$ & $\mathbf{6 0}$ & PT \\
\hline 2 & UTS, MPa & 999 & 883 & 875 & 842 & 837 \\
\hline 3 & Total Elongation, \% & 1349 & 1251 & 1224 & 1186 & 1147 \\
\hline & & 29.94 & 32.67 & 34.60 & 32.76 & 31.00 \\
\hline 4 & Uniform Strain, $\varepsilon_{\mathbf{u}}$ & 0.29 & 0.32 & 0.31 & 0.28 & 0.26 \\
\hline 5 & $\sigma_{\mathrm{UTS}} / \sigma_{\mathrm{Y}}$ & 1.35 & 1.41 & 1.34 & 1.40 & 1.37 \\
\hline
\end{tabular}

Table IV.5

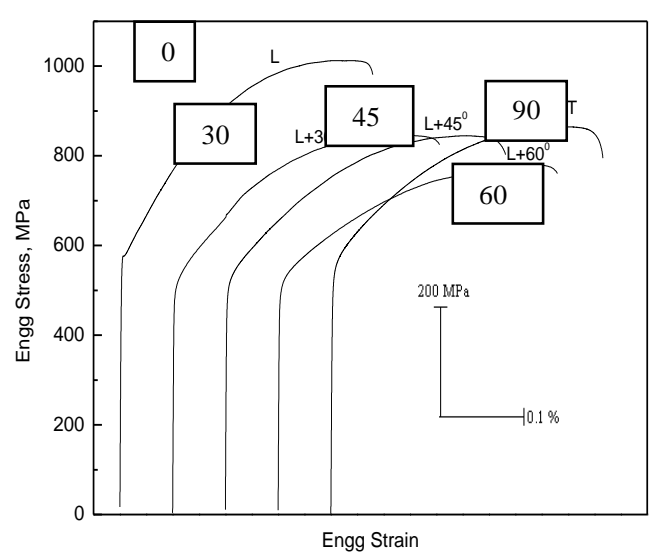

Fig. IV.1

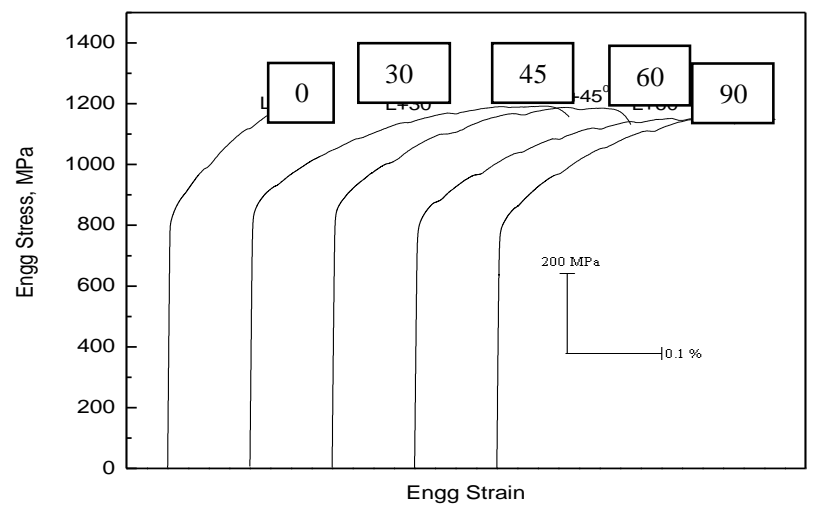

Fig. IV.2 
Fig. IV.1: Engineering Strain - Engineering Stress diagram of alloy 90 of $1 \mathrm{~mm}$ thickness in cold rolled and solution treated condition and Fig. IV.2 is Engineering Strain - Engineering Stress diagram of alloy 90 of $1 \mathrm{~mm}$ thickness in peak aged (Cold Rolled ,Solution Treated at $1110{ }^{0} \mathrm{~K} / 8 \mathrm{~h}$ aged) condition (All tests were conducted at room temperature in laboratory air atmosphere using a strain rate of $10^{-4} \mathrm{~s}^{-1}$ ).

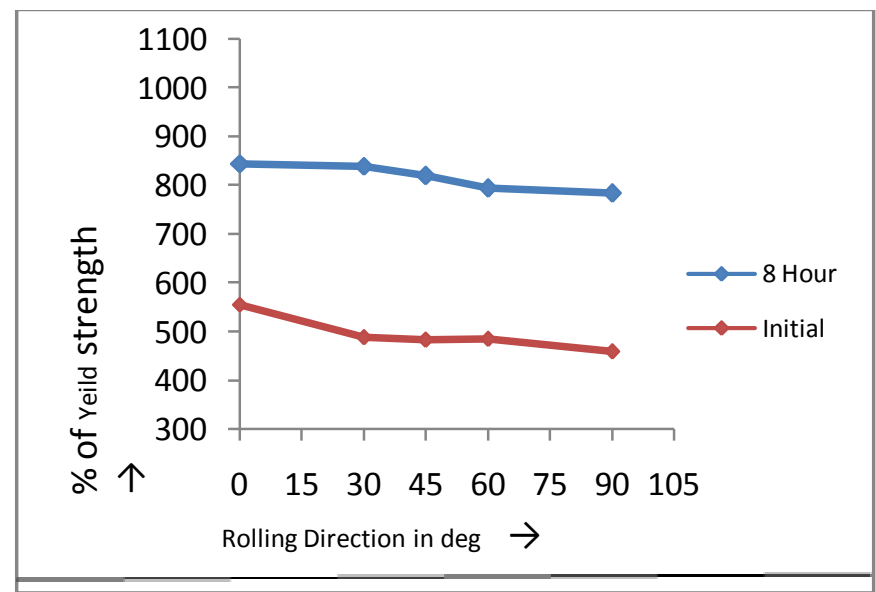

Fig. IV.3( a )

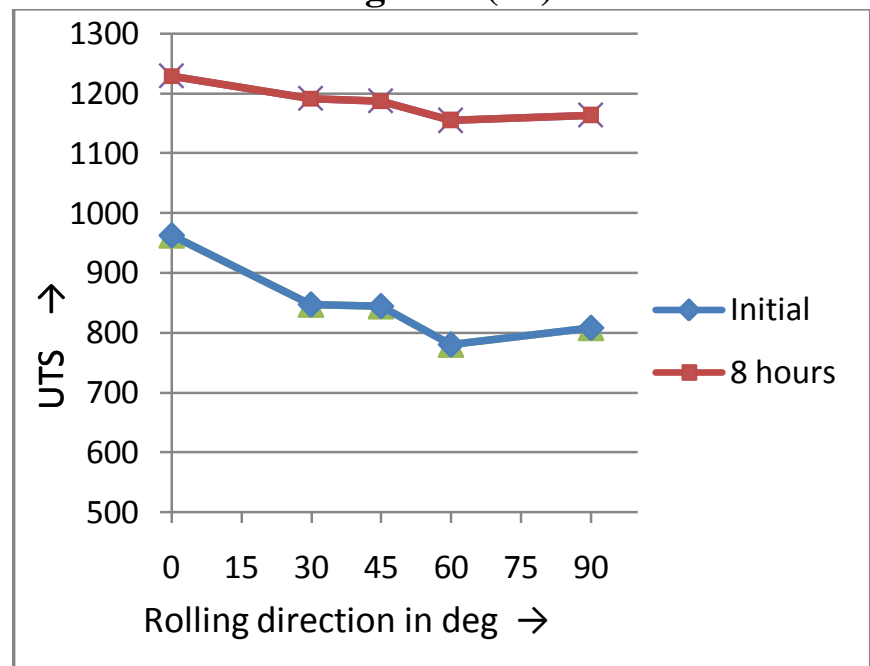

Fig. IV.3(b )

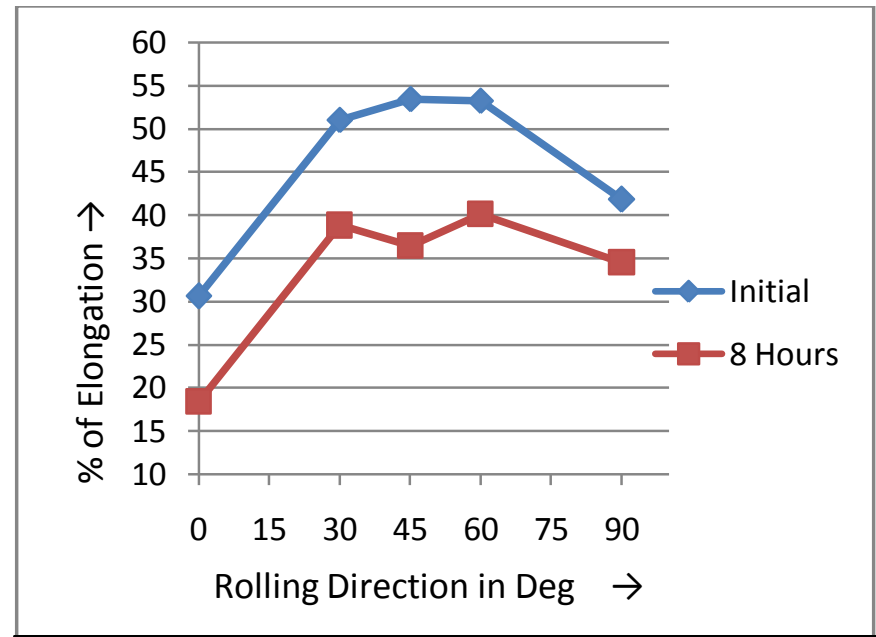

Fig. IV.3 (c ) 
Fig. IV.3: In tensile properties of alloy 90 sheet of $1 \mathrm{~mm}$ thickness in cold rolled, solution treated and aged for $8 \mathrm{~h}$ (peak aged) condition, showing the variation with respect to the rolling direction in (a) \% Yield stress, (b) UTS, (c) Elongation

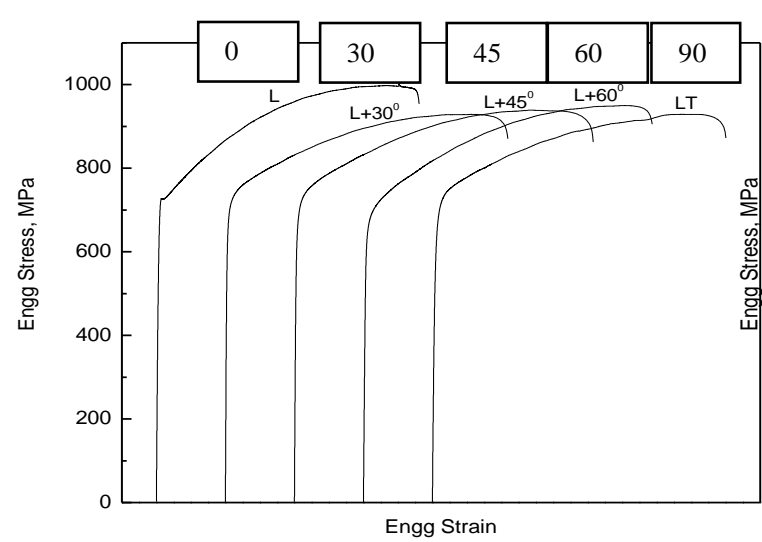

Fig. IV.4

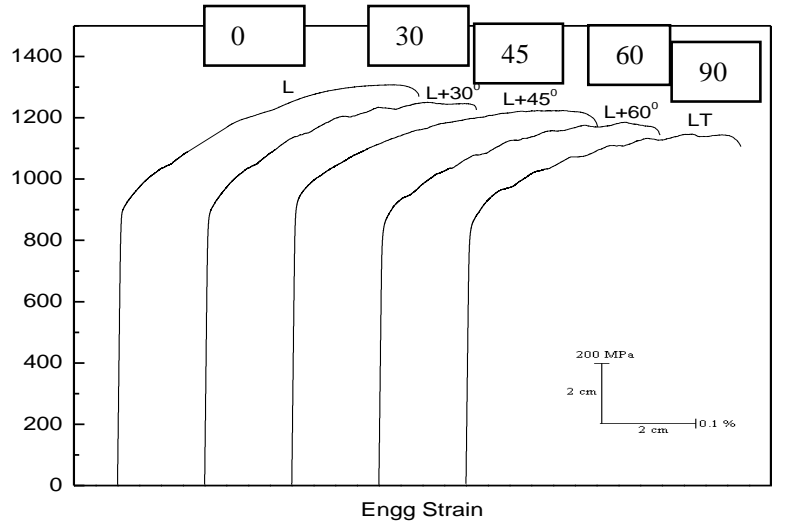

Fig. IV.5

Fig. IV.4: Engineering Strain - Engineering Stress diagram of alloy 90 of $0.5 \mathrm{~mm}$ thickness in cold rolled and solution treated condition and Fig. IV.5 is Engineering Strain - Engineering Stress diagram of alloy 90 of 0.5 $\mathrm{mm}$ thickness in peak aged (Cold Rolled, Solution Treated at $1110{ }^{0} \mathrm{~K} / 8 \mathrm{~h}$ aged) condition.(All tests were conducted at room temperature in laboratory air atmosphere using a strain rate of $10^{-4} \mathrm{~s}^{-1}$ )

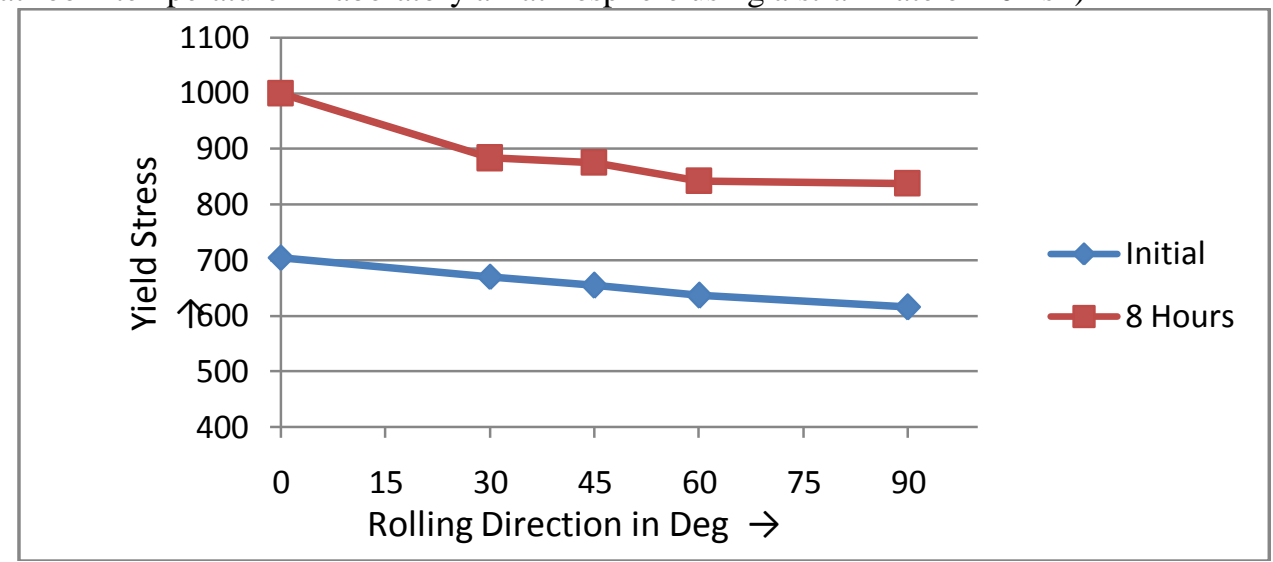

Fig .IV.6 ( a )

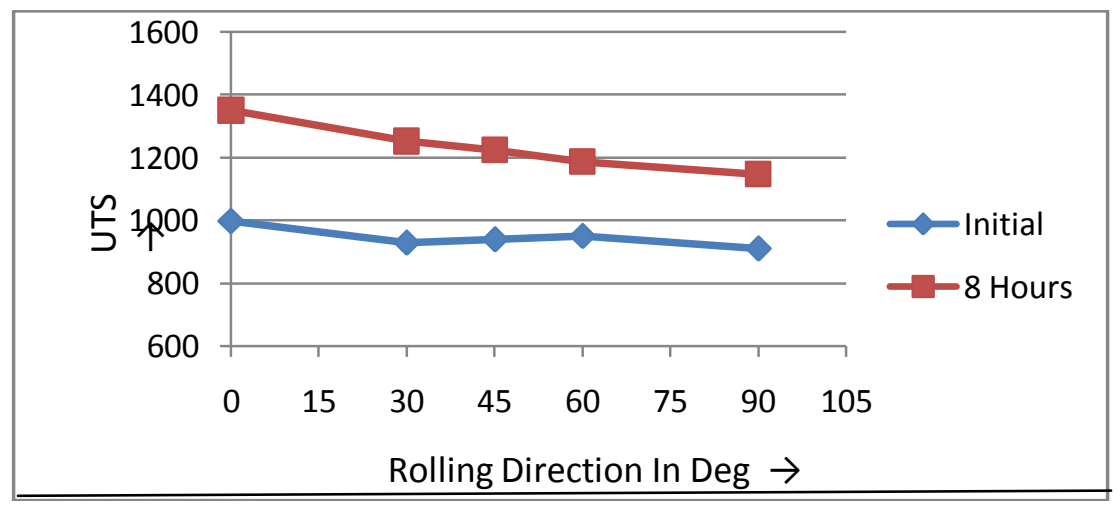

Fig .IV.6 ( b ) 


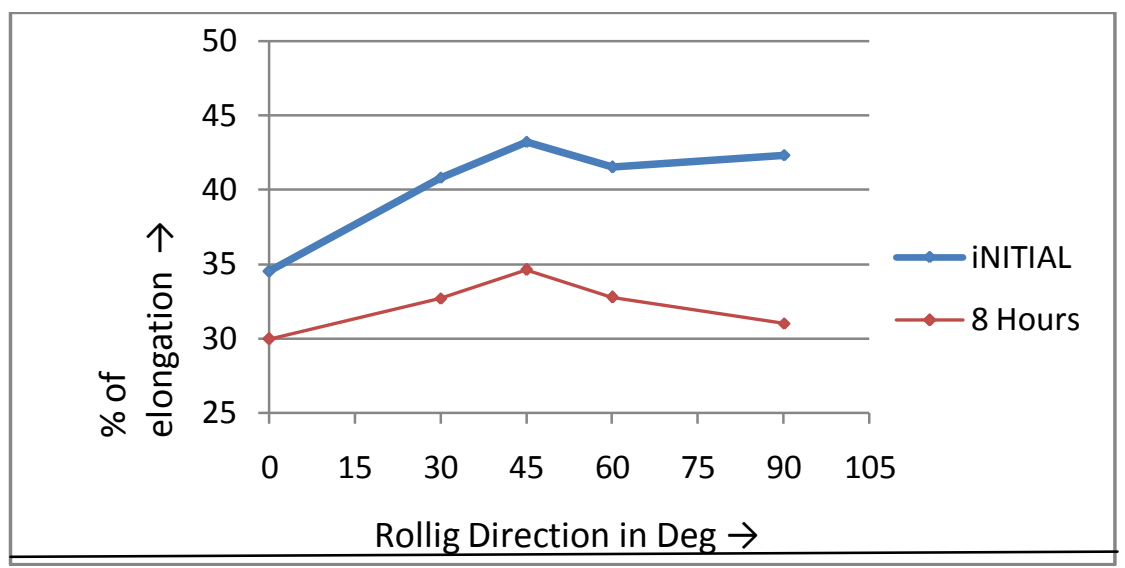

Fig .IV.6 ( c )

Fig. IV.6: In tensile properties of alloy 90 sheet of $0.5 \mathrm{~mm}$ thickness in cold rolled, solution treated and $8 \mathrm{~h}$ (peak aged) condition, showing the variation with respect to the rolling direction in (a) $0.2 \%$ Yield Stress, (b) UTS, (c) Elongation.

As the orientation changes from 0 to $90^{\circ}$, the yield strength and ultimate tensile strength (UTS) decrease gradually. On the other hand, the ductility and the uniform strain increase from 0 to $60^{\circ}$ and then decreases from $60^{\circ}$ to $90^{\circ}$. The orientation dependence in the tensile properties of the $0.5 \mathrm{~mm}$ thickness sheet are similar to the $1 \mathrm{~mm}$ thickness sheet (see data in Tables IV.2 to IV.5). It is normally expected that crystallographic texture and its effect on the directionality in the mechanical properties is nominal in case of highly crystal symmetric FCC material, such as the present alloy 90 sheet. The calculation of Schmid factors as a function of orientation with respect to the rolling direction predicted that in $\mathrm{Al}-\mathrm{Li}$ alloys the minimum in tensile strength and maximum in tensile ductility occur at orientations $50-60^{\circ}$ to the rolling direction $[147,148]$.

\subsection{Effect of ageing on tensile properties and its orientation dependence}

In order to study the effect of ageing, the tensile specimens obtained from both the cold rolled alloy sheets of $1 \mathrm{~mm}$ and $0.5 \mathrm{~mm}$ thickness in differently heat treated conditions, namely Solution Treated, Solution Treated and 1hour aged, Solution Treated and 8hours aged and Solution Treated and 20 hours aged are tested. The engineering stress-strain curves obtained from their testing are shown in Figs. IV.7 and IV.8 and the tensile properties hence determined are given in Tables IV.6 and IV.7. The data in Figs. IV.9 (a)(b)and (c) and Tables IV.6 and IV.7 clearly show that the alloy attains highest strength at $8 \mathrm{~h}$ ageing representing the peak age condition. The strength levels are lower for the ageing times that are below and above 8 hours. Correspondingly, the plastic strain to fracture (elongation) and work hardening exponent (n) values are minimum for this peak aged conditions (Fig. IV.9).

Table IV.6: Tensile properties of alloy 90 sheet in Cold Rolled, Solution treated and different aged conditions of $1 \mathrm{~mm}$ thickness (Test at room temp at an initial Strain Rate of $10^{-4} \mathrm{~s}^{-1}$ ).

\begin{tabular}{|c|l|c|c|c|c|}
\hline \multirow{2}{*}{ S.No } & \multicolumn{1}{|c|}{ Property } & $\begin{array}{c}\text { Solution } \\
\text { Treated }\end{array}$ & $\begin{array}{c}\text { Solution } \\
\text { Treated + 1hr }\end{array}$ & $\begin{array}{c}\text { Solution } \\
\text { Treated + 8hrs }\end{array}$ & $\begin{array}{c}\text { Solution } \\
\text { Treated + 20 } \\
\text { hrs }\end{array}$ \\
\hline 1 & Y.S, MPa & 556 & 792 & 845 & 752 \\
\hline 2 & UTS, MPa & 963 & 1193 & 1230 & 1193 \\
\hline 3 & $\begin{array}{l}\text { Total Elongation, } \\
\%\end{array}$ & 30.6 & 19.50 & 18.40 & 19.66 \\
\hline 4 & Uniform Strain, $\varepsilon_{\mathrm{u}}$ & 0.28 & 0.198 & 0.181 & 0.196 \\
\hline 5 & $\sigma_{\text {UTS } /} \sigma_{\mathrm{Y}}$ & 1.73 & 1.50 & 1.50 & 1.58 \\
\hline
\end{tabular}

Table IV.6 
Table IV.7: Tensile properties of alloy 90 sheet in Cold Rolled ,Solution treated and different aged conditions of $0.5 \mathrm{~mm}$ thickness. (Tests were conducted at room temp at an initial Strain Rate of $10^{-4} \mathrm{~s}^{-1}$ ).

\begin{tabular}{|c|l|c|c|c|c|}
\hline \multirow{2}{*}{ S.No } & \multicolumn{1}{|c|}{ Property } & $\begin{array}{c}\text { Solution } \\
\text { Treated }\end{array}$ & $\begin{array}{c}\text { Solution } \\
\text { Treated + } \\
\mathbf{1 h r}\end{array}$ & $\begin{array}{c}\text { Solution } \\
\text { Treated + } \\
\text { 8hrs }\end{array}$ & $\begin{array}{c}\text { Solution } \\
\text { Treated + 20 } \\
\text { hrs }\end{array}$ \\
\cline { 3 - 6 } & Y.S, M Pa & 704 & 883 & 999 & 816 \\
\hline 2 & UTS, M Pa & 998 & 1251 & 1349 & 1241 \\
\hline 3 & $\begin{array}{l}\text { Total Elongation, } \\
\%\end{array}$ & 34.5 & 30.67 & 29.94 & 26.64 \\
\hline 4 & $\begin{array}{l}\text { Uniform Strain, } \\
\varepsilon_{\mathrm{u}}\end{array}$ & 0.35 & 0.25 & 0.29 & 0.27 \\
\hline 5 & $\sigma_{\mathrm{UTS} /} \sigma_{\mathrm{Y}}$ & 1.42 & 1.41 & 1.35 & 1.52 \\
\hline
\end{tabular}

\section{Table IV.7}
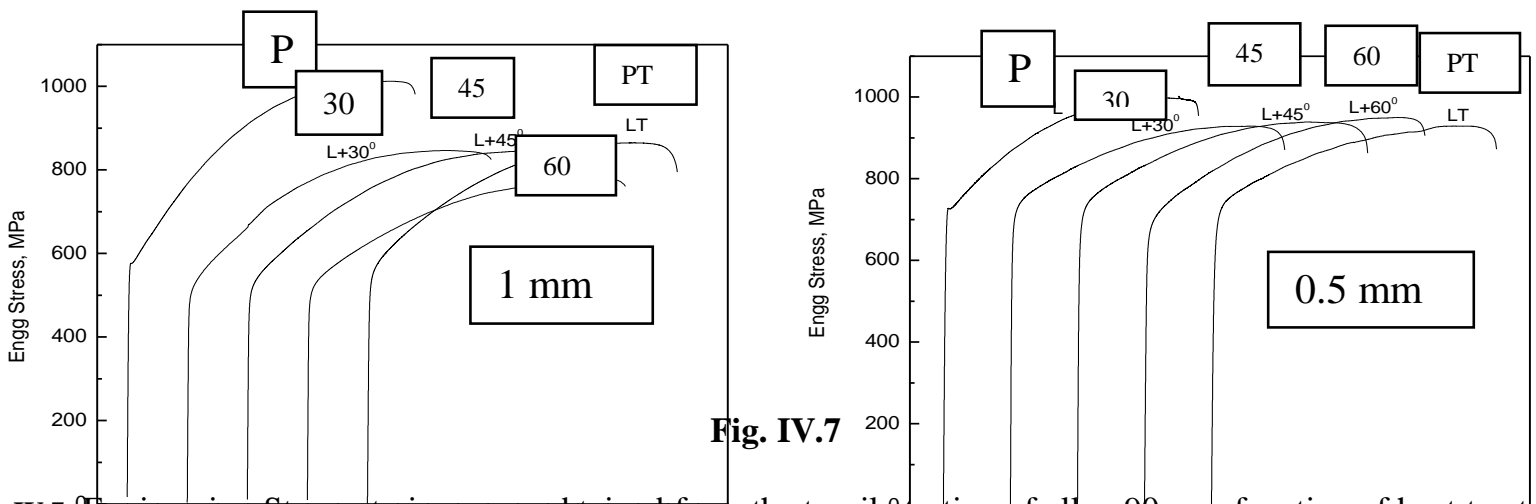

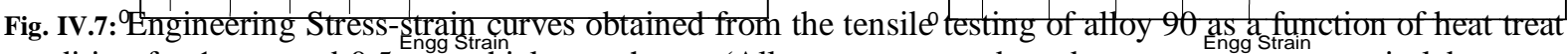
condition for $1 \mathrm{~mm}$ and $0.5 \mathrm{~mm}$ thickness sheets. (All tests were conducted at room temperature in laboratory air atmosphere using a strain rate of $10^{-4} \mathrm{~s}^{-1}$ )

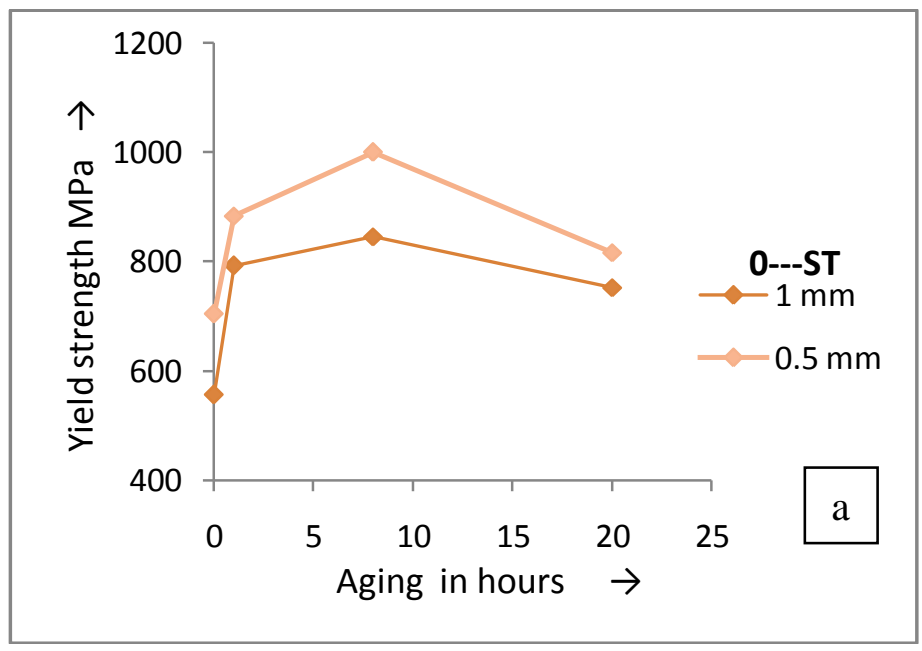



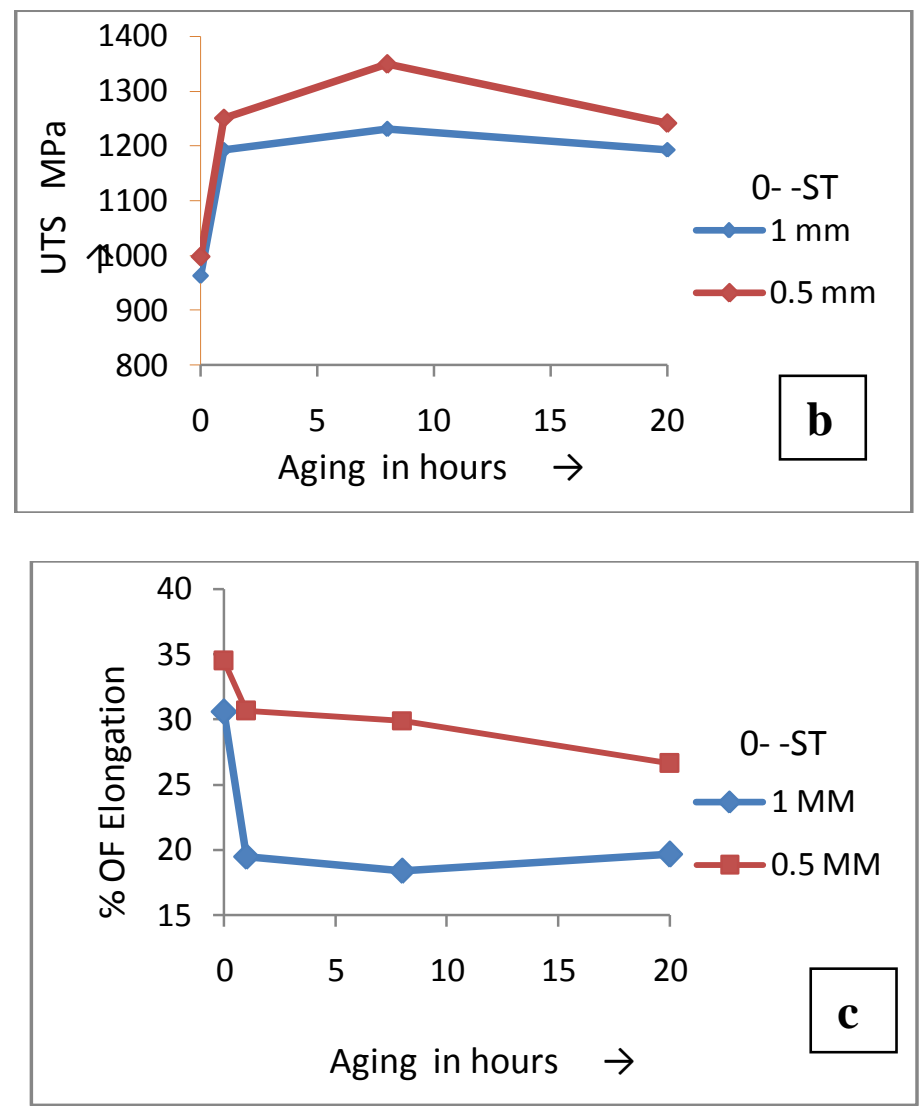

Fig. IV.9 a,b and c

Fig. IV.9: In tensile properties (a) $0.2 \%$ Yield Stress, (b) UTS, and (c) Elongation of alloy 90 sheets of $1 \mathrm{~mm}$ and $0.5 \mathrm{~mm}$ thickness in solution treated and different aged conditions. (All tests were conducted at room temperature in laboratory air atmosphere using a strain rate of $10^{-4} \mathrm{~s}^{-1}$ ).

\section{Fracture behavior}

The fractured surfaces of the tensile tested specimens were observed under scanning electron microscope to determine the mode of fracture. The fracture features observed for the two sheets $(1 \mathrm{~mm}$ and $0.5 \mathrm{~mm}$ thickness) and two heat treated conditions (Cold Rolled, Solution Treated and peak aged), the fractographs of 1 $\mathrm{mm}$ and $0.5 \mathrm{~mm}$ thickness specimens in Solution Treated conditions are produced here.

The fractographs at lower magnification (Figs. IV.10 and IV.12) clearly show that the alloy sheet under tensile loading fail predominantly by high energy, ductile dimple fracture with a small extent of shear fracture.

The dimples observed were found to be distinctly of two sizes. The coarse dimples are of average dia of 2-5 $\square \mathrm{m}$ and their size as well as number density decrease initially as the orientation changes from $0-45^{\circ}$ and then increases again. On the other hand, the fine micro dimples, which are uniformly present and could be seen clearly only at higher magnification (Figs. IV.11 and IV.13), are found to be of similar density and size (2-4 $\square \mathrm{m}$ ) in all the 5 test directions. The two size distribution of dimples (coarse and fine/micro dimples) leading to gross dimple fracture could have resulted from the void-nucleation, growth and their coalescence. The void nucleation particles presumably are large sized $\mathrm{MC}$ and/or $\mathrm{M}_{23} \mathrm{C}_{6}$ carbides in case of coarse dimples (whose density and special distribution match well with those of the carbides) and $\square$ ' precipitates in ase of the fine and uniformly distributed micro-dimples. The observations are similar for all other conditions, i.e., $1 \mathrm{~mm}$ and 0.5 $\mathrm{mm}$ thick sheets in cold rolled, Solution Treated and 8h (peak aged) aged condition. 
Fig. IV.10 to 13: High and low magnification macrofractographical features of tensile tested specimens of alloy 90 sheet of $1 \mathrm{~mm}$ and $0.5 \mathrm{~mm}$ thickness in different test directions.
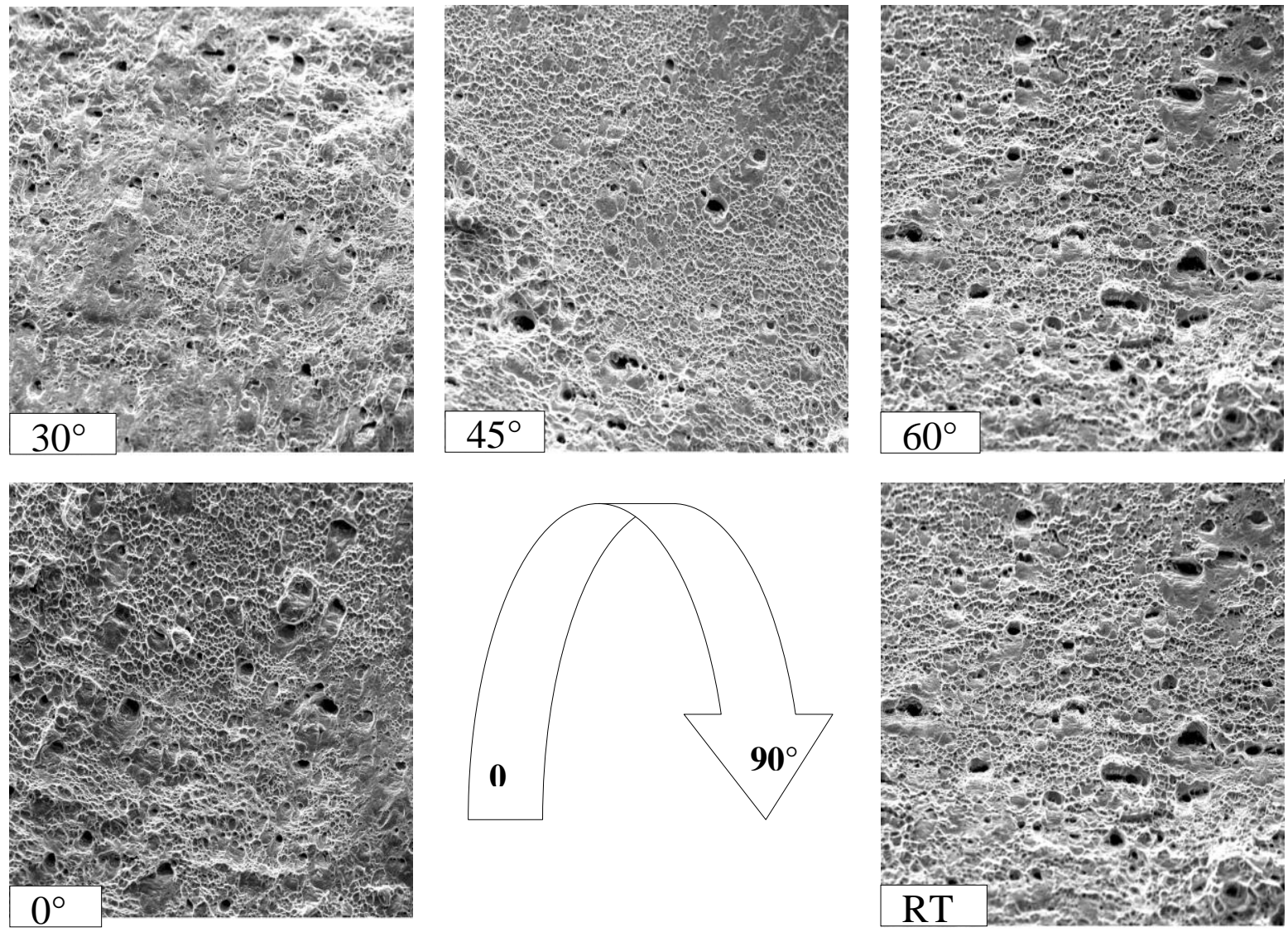

\section{Fig. IV.10}

(IN DEGREES

SPECIMEN ORIENTATION

Fig. IV-10: Low magnification macrofractographical features of tensile tested specimens of Alloy 90 sheet of $1 \mathrm{~mm}$ thickness in different test directions.
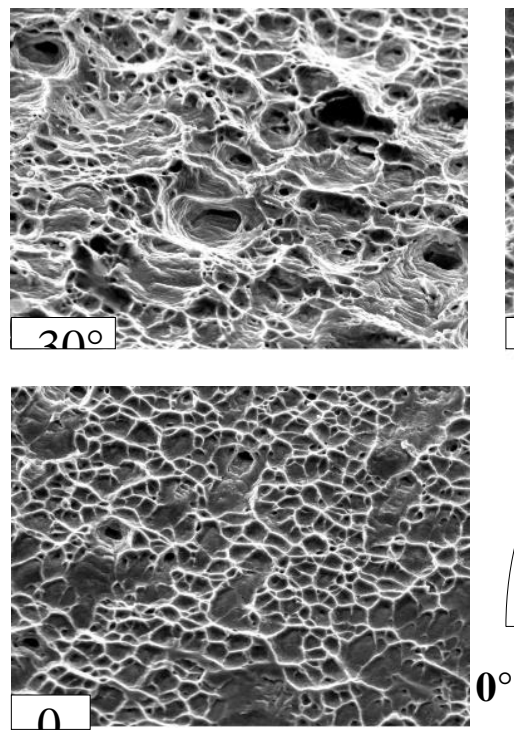
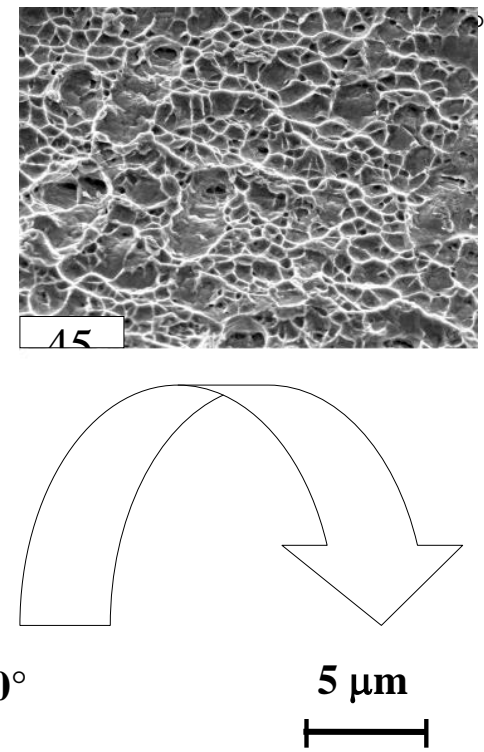

Fig. IV.11
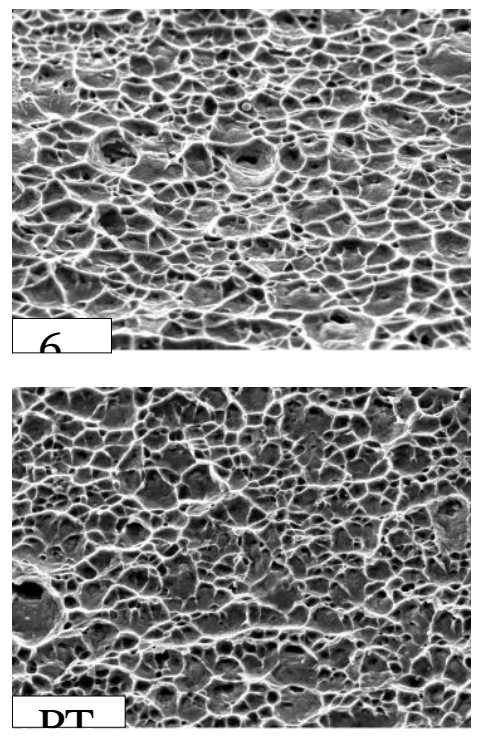

SPECIMEN ORIENTATION 
(IN DEGREES)

Fig. IV.11: High magnification macrofractographical features of tensile tested specimens of Alloy 90 sheet of $1 \mathrm{~mm}$ thickness in different test directions.
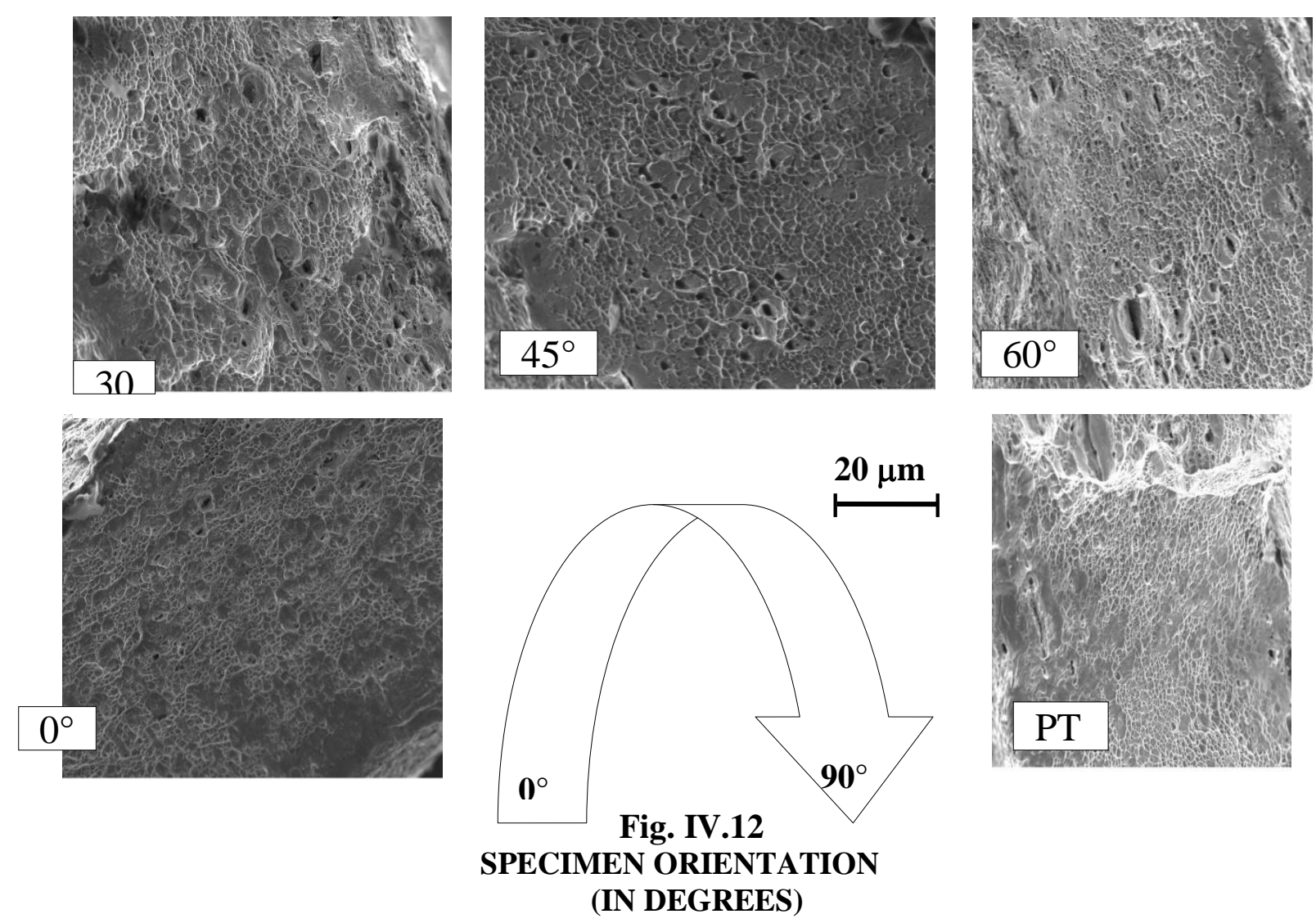

Fig. IV.12: Low magnification macrofractographical features of tensile tested specimens Alloy 90 sheet of $0.5 \mathrm{~mm}$ thickness in different test directions.
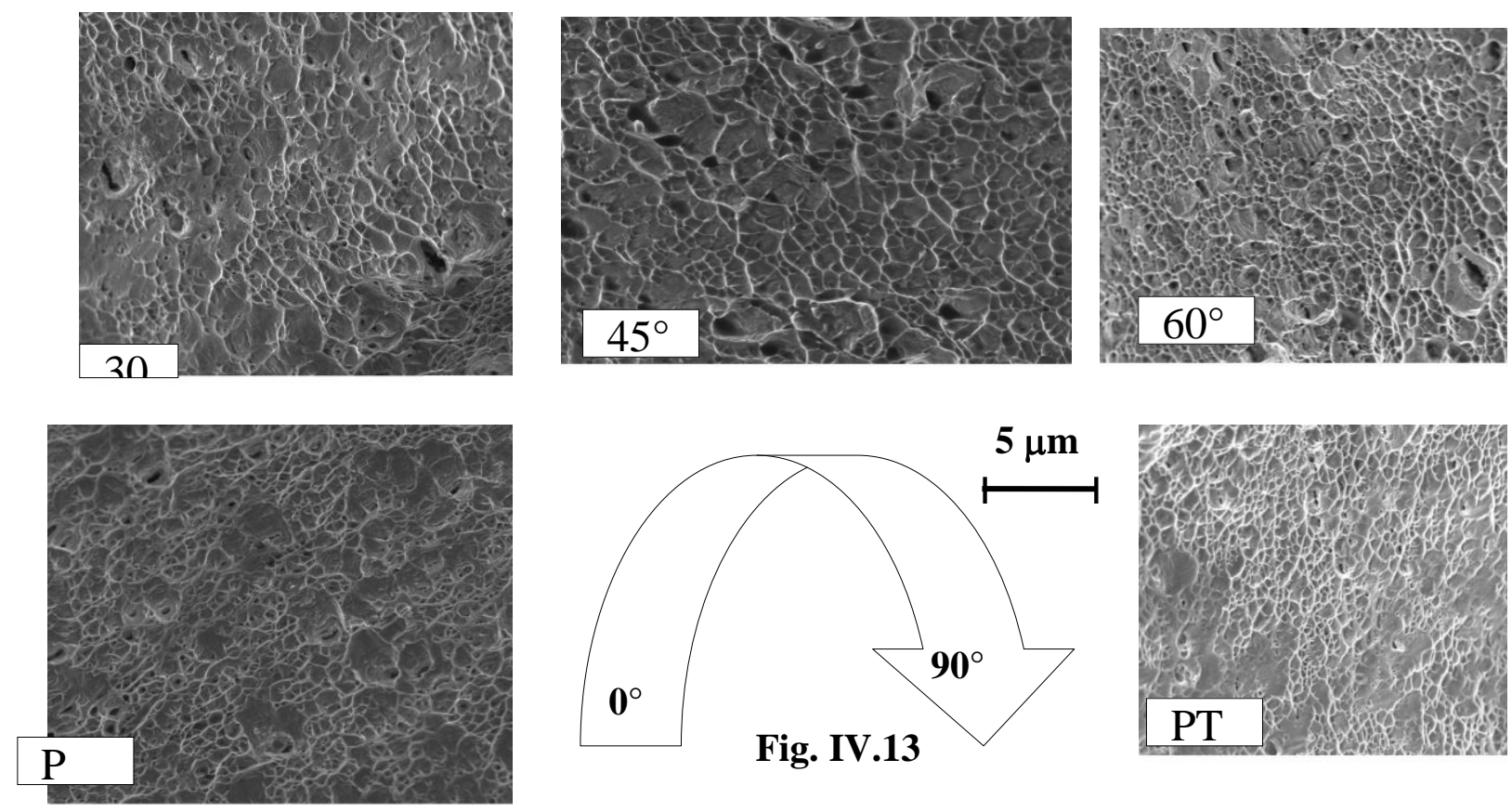

SPECIMEN ORIENTATION

(IN DEGREES) 
Fig. IV.13: High magnification macrofractographical features of tensile tested specimens of alloy 90 sheet of $0.5 \mathrm{~mm}$ thickness in different test directions.

\section{Technological Implications}

An analyses of the data summarily presented in Table IV.10 indicates the trends in the degree of anisotropy. These data clearly show that the degree of anisotropy is significantly higher for the solution treated condition, which values decrease considerably with subsequent ageing. The degree of anisotropy in tensile properties (analyzed wrt to comparing of properties in P direction with those of $\mathrm{PT}$ or $45^{\circ} / 60^{\circ}$ ) is nearly $20-30 \%$ higher in the Cold Rolled and Solution Treated condition as compared to the peak aged condition. This could be due to the influence of varied dislocation - $\square$ ' precipitate interaction with or without the additional contribution from the change in texture.

Table IV.10

\begin{tabular}{|c|c|c|c|c|}
\hline \multirow{3}{*}{ Description } & \multicolumn{4}{|c|}{ Value } \\
\hline & \multicolumn{2}{|r|}{$1 \mathrm{~mm}$} & \multicolumn{2}{|c|}{$0.5 \mathrm{~mm}$} \\
\hline & $\begin{array}{l}\text { Solution } \\
\text { Treated }\end{array}$ & $\begin{array}{l}\text { Solution Treated } \\
\text { and } 8 \mathrm{~h}\end{array}$ & $\begin{array}{l}\text { Solution } \\
\text { Treated }\end{array}$ & $\begin{array}{l}\text { Solution } \\
\text { Treated and } \\
\mathbf{8 h}\end{array}$ \\
\hline $\begin{array}{l}\text { Tensile yield strength, in } \mathrm{MPa} \\
\text { L Direction } \\
\text { LT Direction }\end{array}$ & $\begin{array}{l}556 \\
460 \\
\end{array}$ & $\begin{array}{l}845 \\
784 \\
\end{array}$ & $\begin{array}{l}704 \\
615 \\
\end{array}$ & $\begin{array}{l}999 \\
837\end{array}$ \\
\hline $\begin{array}{l}\text { Ultimate tensile strength, in } \mathrm{MPa} \\
\text { L Direction } \\
\text { LT Direction } \\
\end{array}$ & $\begin{array}{l}963 \\
808\end{array}$ & $\begin{array}{l}1230 \\
1164\end{array}$ & $\begin{array}{l}998 \\
909 \\
\end{array}$ & $\begin{array}{l}1349 \\
1147\end{array}$ \\
\hline $\begin{array}{l}\text { Yield stress from yield locus, in MPa } \\
\text { L Direction - Tension } \\
\text { L Direction - Compression }\end{array}$ & $\begin{array}{l}2826.0 \\
3592.6\end{array}$ & $\begin{array}{l}4292.7 \\
4341.5\end{array}$ & $\begin{array}{l}3353.0 \\
3526.3\end{array}$ & $\begin{array}{l}4400.0 \\
4881.3\end{array}$ \\
\hline $\begin{array}{l}\text { Yield stress from yield locus, in MPa } \\
\text { LT Direction - Tension }\left(\square_{\mathrm{x}}\right) \\
\text { LT Direction - Compression } \\
\left(\square_{\mathrm{v}}\right)\end{array}$ & $\begin{array}{l}3179.5 \\
2948.7\end{array}$ & $\begin{array}{l}4230.7 \\
4461.5\end{array}$ & $\begin{array}{l}3411.7 \\
3842.1\end{array}$ & $\begin{array}{l}4450.0 \\
4508.5\end{array}$ \\
\hline
\end{tabular}

\section{Conclusion}

1. The aged alloy sheets exhibited higher strength levels (\% of YS, UTS, KHN, strengths from yield locus), lower ductility (\% elongation) as well as lower degrees of work hardening exponents and most importantly lower degrees of anisotropy.

2. The alloy sheets in both heat treat conditions were found to fail predominantly by higher energy, ductile dimple fracture with macro (due to coarse $\mathrm{MC}$ and $\mathrm{M}_{23} \mathrm{C}_{6}$ carbides) and micro (due to uniformly distributed, copious $\square$ ' precipitates) dimples with minor components of shear fracture

\section{References}

[1]. Singh AK, Saha GG, Gokhale AA and Ray RK, Evolution of texture and microstructure in a thermo-mechanically processed Al-LiCu-Mg alloy, Metall. Mater. Trans. A, Vol. 29A (1998) pp. 665-675.

[2]. Howard-White FB, Nickel- An historical review, VanNostrand, Princeton, (1963)

[3]. Donachie MJ, Superalloys, American Society for Metals (1984).

[4]. Sims CT, Stoloff NS and Hagel WC, Superalloys II, John Willey and Sons, New York, (1987).

[5]. McLean M, Webster GA, Nabarro FRN and Cottrel A, Nickel based Superalloys: Current status and potential, Phil. Trans. Royal Soc. London, Vol. 351 (1995) pp. 419-43

[6]. Joseph R. Davis, S. L. Semiatin, ASM Metals Handbook, Forming and Forging, ASM International, 9th edition, Vol. 14 (1989) pp. 891-892.

[7]. Kotthaus H, An investigation of transportability of test results from models to full scale tooling for deep drawing of round scaled components, Dr. Ing. Thesis, Technishe Hochschule, Stuttgart (1955).

[8]. Made W and Deh R, Deep-drawing tests and failure of soft, unalloyed steels, Manufacturing Technology, Vol. 17 (1967) pp. 665672.

[9]. Koelzer H, The behavior of deep drawing sheets as a function of testing methods, Dr.Ing thesis, Technishe Hochule, Braunschwig, (1979).

[10]. Ludwigson DG, Modified stress-strain relation for F.C.C. metals and alloys, Metall. Trans., Vol. 2 (1971) pp. 2825-2828.

[11]. Sivaprasad PV, Venugopal S and Venkadesan S, Work hardening behaviour of the Ni-Fe based superalloy IN718, Metallurgica and Materials Trans. A, Vol. 28A (1997) pp. 171-178.

[12]. Kuo VWC and Starke EA, The development of two texture variants and their effect on the mechanical behavior of a high strength P/M aluminium alloy, Metall. Trans. A, Vol. 16A (1985) pp. 1089-1103.

[13]. Jata KV, Panchandeeswaran S and Vasudevan AK, Evolution of texture, microstructure and mechanical property anisotropy in an Al-Li-Cu alloy, Material Science Engineering, Vol. A257 (1998) pp. 37-46. 